\title{
Preventive measures and management of COVID-19 in pregnancy
}

\author{
Sumaira Omer ${ }^{1} \cdot$ Salamat $\mathrm{Ali}^{2} \cdot$ Zaheer ud Din Babar $^{3}$
}

Published online: 9 April 2020

(c) Springer Nature Switzerland AG 2020

\section{Introduction}

The novel severe acute respiratory syndrome (SARS) coronavirus 2 (SARS-CoV-2; also known as 2019-nCoV) has played havoc worldwide, beginning with Wuhan, China in December 2019. As of 17 March 2020, there are 153 countries who have reported cases of infection caused by this virus [i.e., coronavirus disease-2019 (COVID-19)], with Italy becoming the new epicentre [1]. COVID-19 is a global public health emergency, and could cause devastating health issues during pregnancy. Pregnant women have a high propensity to acquire this infection due to their altered physiological and immunological function.

Previous studies have indicated that SARS during gestation is linked with a high risk of spontaneous miscarriage, preterm birth and intrauterine growth restriction [2]. To date, studies in pregnant women with COVID-19 have indicated few maternal and neonatal complications [3], but more concrete evidence is required as these studies involved a small number of women over a short period [4]. Importantly, viral respiratory illnesses, such as influenza, can easily develop during pregnancy, which means pregnant women may be more vulnerable to COVID-19 and require prioritized medical care.

Interim COVID-19 guidelines for the effective counselling and education of pregnant women are currently available from the Centers for Disease Control and Prevention (CDC) and the World Health Organization (WHO) [5, 6]. Recommendations, which were published following the COVID epidemic in Wuhan, are also available from

Sumaira Omer

sammaraomer@gmail.com

1 Department of Pharmacy Administration and Clinical Pharmacy, Xian Jiatong University, Xi' an, China

2 Services Institute of Medical Sciences, Lahore, Pakistan

3 Centre of Pharmaceutical Policy and Practice Research, University of Huddersfield, Huddersfield, West Yorkshire, UK
Chinese experts $[7,8]$. This commentary reviews the available information on managing COVID-19 during pregnancy to preserve the health of mothers and children in this critical situation.

\section{Characteristics and transmission of 2019-nCoV}

2019-nCoV is an RNA single-stranded, non-segmented, enveloped virus belonging to a diverse group of viruses that are zoonotic (i.e., they are pathogens that can live in both animals and humans). Until now, seven corona viruses have been identified that could infect humans [9]. SARS-CoV-1 and Middle East respiratory syndrome coronavirus (MERS$\mathrm{CoV}$ ), two deadly pathogens, belong to the same viral group as 2019-nCoV. As this pathogen has a receptor-binding domain structure similar to that of SARS-CoV-1, it is likely that COVID-19 and SARS have a similar pathogenesis [10].

These viruses appear to be mainly spread via person-toperson contact [11]. The route of transmission is primarily via respiratory droplets from the infected person into air, which are then deposited onto nearby surfaces. The virus could potentially transfer to individuals within a distance of $<2 \mathrm{~m}$ ( 6 feet) of the infected person [12]. As the virus can survive on non-living surfaces, it is essential to frequently clean touched surfaces [13]. To date, no medications or vaccines are approved to treat or prevent COVID-19 [14]. Therefore, implementation of preventive measures is important to avoid its further spread.

\section{Symptoms and diagnosis of COVID-19}

The onset of symptoms is usually within 14 days of exposure. COVID-19 symptoms range from mild to severe, and commonly include shortness of breath, cough, myalgia, fever and severe pneumonia. Injury to vital organs (kidney, heart, liver) has also been observed [15]. The severity of infection may depend on the underlying health of the individual [16], with patients with pre-existing illnesses, such as diabetes 
and lung disease, as well as the elderly, being more prone to the rapid development of COVID-19.

Diagnosis of COVID-19 is mainly based on computed tomography (CT) scans and reverse transcription polymerase chain reaction (RT-PCR). This test is routinely employed for the detection of viruses responsible for respiratory illnesses [17]. In the RT-PCR technique, viral isolates are used as a primary substrate to perform an assay that identifies a specific virus and its gene sequence [18]. A CT scan is considered more sensitive than RT-PCR, and can be used to confirm a positive RT-PCR test [19]. To conduct RT-PCR, a sample taken from throat swabs, urine, saliva or stool can be used. Usually the nucleic acid test is repeated for a single patient in order to get accurate results. Two tests are performed successively at a gap of $24 \mathrm{~h}$ when the virus is not observed in the throat swab sample. If RT-PCR is not available, a serological test could also be use for diagnostic examination [15].

\section{Precautionary measures during pregnancy}

Preventive measures, including frequent hand washing, refraining from excessive outdoor activities unless an emergency, and avoiding infected individuals, crowded places and public gatherings, should be strictly followed by pregnant women. They should check their temperature regularly and immediately inform their doctor if they experience shortness of breath, cough or fever [14]. Moreover, women who have a travel history or COVID-19 symptoms should be kept in isolation for at least 14 days. The National Health Commission of China proposed that neonates from mothers who are confirmed or suspected cases should be kept under observation and not breastfed [8]. However, no evidence is currently available to confirm the transfer of 2019-nCoV to breast milk.

Pregnant women should closely monitor their vital signs (pulse rate, respiration rate and temperature). Importantly, they should inform their maternity-care provider regarding their health status and seek advice regularly. Extracorporeal membrane oxygenation and oxygen inhalation (60-100\% concentration with a flow rate of $40 \mathrm{~L} / \mathrm{min}$ ) should be used if hypoxia occurs [15].

\section{Managing COVID-19 in pregnancy}

For effective management, pregnant women with suspected COVID-19 should be isolated and then transferred to a hospital equipped with sufficient health facilities and fully trained clinicians to take proper care of critically ill obstetric patients. In order to provide appropriate treatment after complete examination [15], pregnant women can usually be categorized as having:
- Mild disease (i.e., symptomatic with stable vital signs).

- Severe disease (i.e., respiration rate $\geq 30 / \mathrm{min}$, resting saturated $\mathrm{O}_{2} \leq 93 \%$, arterial blood oxygen partial pressure/oxygen concentration $\leq 300 \mathrm{mmHg}$ ).

- Critical disease (i.e., shock with organ failure, respiratory failure requiring mechanical ventilation or refractory hypoxaemia requiring extra-corporal membrane oxygenation).

\section{Pharmaceutical care}

No drug is currently approved to treat COVID-19, and presently, there is no effective coronavirus drug, and unethical usage of drugs should be avoided [7]. However, twice-daily antiviral treatment with lopinavir/ritonavir $(400 \mathrm{mg} / 100 \mathrm{mg})+\alpha$-interferon ( 5 million IU in $2 \mathrm{~mL}$ of sterile water for injection) has shown improvements in clinical condition in some cases [15]. This regimen may also be used to treat pregnant women, despite lopinavir/ritonavir being a pregnancy category $\mathrm{C}$ drug (i.e., use in pregnancy only when the potential benefits outweigh the potential risks).

COVID-19 causes extensive alveolar damage, which, in turn, increases the risk of secondary bacterial infection. On confirmation of secondary bacterial infection, intravenous ceftriaxone should be administered [15].

Corticosteroids should not be used to treat COVID-19, as they obstruct the clearance of virus from the body. Therefore, methylprednisolone should be used cautiously and only in critically ill patients with hypoxic conditions [15].

\section{Neonatal care}

2019-nCoV is extremely contagious [20]. It may have a disastrous health impact on neonates, causing symptoms such as respiratory distress (shortness of breath), high heart rate and gastrointestinal distress. Reportedly, initial symptoms of neonates from infected mothers were shortness of breath, cough and fever, but vertical transmission of infection (the transfer of the pathogen from infected mother to infant during the period before or after birth, particularly via germ cell and placental blood) has not been confirmed [3, 7]. Based on the results of a retrospective study of ten neonates born to nine pregnant woman with confirmed COVID-19 in China, vertical transmission of 2019-nCov to neonates has not yet been confirmed [3]. To decrease the risk of vertical transmission, delayed cord clamping (DCC) is not recommended. Moreover, mother-baby contact is also not advisable [7]. However, as a precautionary measure, neonates should be kept isolated for 14 days. When breastfeeding, it is advisable 
to use a breast pump to minimize the risk of transmitting the infection [21].

\section{What concerns need to be addressed?}

Viral infections pose serious consequences for maternal and neonatal health. Over the last 2 decades, human life was threatened by infections caused by SARS-CoV- 1 and MERS-CoV, but 2019-nCoV is responsible for more illness than these viruses. Thus far, it appears that the clinical presentation of COVID-19 does not differ between pregnant and non-pregnant women [22]. Although more robust research is required, fears regarding the vertical transmission of 2019$\mathrm{nCoV}$ and/or teratogenicity should not lead to abortion.

Preventive anti-viral measures must be properly implemented to avoid further spreading of 2019-nCoV and, therefore, of COVID-19. Everyone should maintain basic personal hygiene. Initial screening should be performed at hospital entrances, and suspected cases should be isolated. Special attention, as well as prioritized care, should be offered to pregnant women based on their health status. Healthcare professionals should be given specialized clothing and equipment, and should follow the standard procedure for donning, doffing and disposal of personal protective equipment [23].

Finally, collaboration between nations is imperative to tackle the burden of COVID-19. Experts and healthcare professionals should share useful information and effective schemes to curb the rate of outbreaks, especially in regions with few health facilities. Surveillance systems for reporting all significant maternal and fetal data in pregnant women with COVID-19 should also be established.

\section{Take home messages}

- Keep up to date with the latest COVID-19 information and guidelines from the CDC and WHO.

- Take preventive measures, specifically in pregnant women, to control further spread of COVID-19.

- Focus on symptomatic treatment, as there is no recommended treatment for COVID-19.

- Promote effective communication between healthcare professionals to detect suspected COVID-19 during pregnancy.

- Provide prioritized care for pregnant women, thereby preventing further promulgation of the infection in neonates.

Author contributions SO and ZDB designed the initial concept. SO and SA made substantial contributions during report collection and writing. ZDB provided expert advice regarding relevant studies. Finally, all authors reviewed the drafts prior to submission.

\section{Compliance with ethical standards}

Funding No funding was received for the preparation or publication of this article.

Conflict of interest The authors declare no conflicts of interest.

\section{References}

1. Top 10 countries outside China with highest number of coronavirus cases. Available from: https://www.forbes.com/sites/kenra poza/2020/03/05/top-10-countries-outside-china-with-highestnumber-of-coronavirus-cases/\#10ce66c0661b. Accessed $21 \mathrm{Feb}$ 2020.

2. Wong SF, Chow KM, Leung TN, et al. Pregnancy and perinatal outcomes of women with severe acute respiratory syndrome. Am J Obstet Gynecol. 2020;191:292-7.

3. Zhu H, Wang L, Fang C, et al. Clinical analysis of 10 neonates born to mothers with 2019-nCoV pneumonia. Transl Pediatr. 2020;9:51-60.

4. Qiao J. What are the risks of COVID-19 infection in pregnant women? Lancet. 2020;395:760-2.

5. Centers for Disease Control and Prevention. Interim infection prevention and control recommendations for patients with suspected or confirmed coronavirus disease 2019 (COVID-19) in healthcare settings. Available from: https://www.cdc.gov/coronavirus/2019ncov/infection-control/control-recommendations.html?. Accessed 19 Mar 2020.

6. World Health Organization (WHO). Clinical management of severe acute respiratory infection when novel coronavirus ( $\mathrm{nCoV}$ ) infection is suspected: interim guidance. Available from: https:// www.who.int/publications-detail/clinical-management-of-sever e-acute-respiratory-infection-when-novel-coronavirus-(ncov)infection-is-suspected. Accessed 14 Mar 2020.

7. Wang L, Shi Y, Xiao T, et al. Chinese expert consensus on the perinatal and neonatal management for the prevention and control of the 2019 novel coronavirus infection (first edition). Ann Transl Med. 2020;8:47.

8. National Health Commission of the People's Republic of China. Notice on strengthening maternal disease treatment and safe midwifery during the prevention and control of new coronavirus pneumonia. Available from: https:/www.nhc.gov.cn/xcs/ zhengcwj/202002/4f80657b346e4d6ba76e2cfc3888c630.shtml. Accessed 20 Feb 2020.

9. Babymed. Coronavirus 2019-nCoV COVID-19 and pregnancy. Available from: https://www.babymed.com/infections/coronaviru s-ncov-COVID-19-and-pregnancy. Accessed 9 Mar 2020.

10. Lu R, Zhao X, Li J, et al. Genomic characterisation and epidemiology of 2019 novel coronavirus: implications for virus origins and receptor binding. Lancet. 2020;395:565-74.

11. World Health Organization. Coronavirus. Available from: https:// www.who.int/health-topics/coronavirus. Accessed 17 Mar 2020.

12. Medline Plus. Coronavirus infections. Available from: https:// medlineplus.gov/coronavirusinfections.html. Accessed 24 Jan 2020.

13. Centers for Disease Control and Prevention. Disinfecting your home if someone is sick. Available from: https://www.cdc.gov/ coronavirus/2019-ncov/prepare/disinfecting-your-home.html. Accessed 17 Mar 2020. 
14. Centers for disease control and prevention. Coronavirus disease 2019 (COVID-19) situation summary. Available from: https:// www.cdc.gov/coronavirus/2019-nCoV/summary.html. Accessed 7 Mar 2020.

15. Liang H, Acharya G. Novel corona virus disease (COVID-19) in pregnancy: what clinical recommendations to follow? Acta Obstet Gynecol Scand. 2020. https://doi.org/10.1111/aogs.13836.

16. Centers for Disease Control and Prevention. Coronavirus disease 2019 (COVID-19). Available from: https://www.cdc.gov/coron avirus/2019-ncov/symptoms-testing/symptoms.html. Accessed 14 Mar 2020.

17. Corman VM, Landt O, Kaiser M, et al. Detection of 2019 novel coronavirus (2019-nCoV) by real-time RT-PCR. Euro Surveill. 2020;25.

18. Emery SL, Erdman DD, Bowen MD, et al. Real-time reverse transcription-polymerase chain reaction assay for SARS-associated coronavirus. Emerg Infect Dis. 2004;10:311-6.

19. Ai T, Yang Z, Hou H, et al. Correlation of chest CT and RTPCR testing in coronavirus disease 2019 (COVID-19) in China: a report of 1014 cases. Radiology. 2020. https://doi.org/10.1148/ radiol.2020200642:200642.

20. Chan JF, Kok KH, Zhu Z, et al. Genomic characterization of the 2019 novel human-pathogenic coronavirus isolated from a patient with atypical pneumonia after visiting Wuhan. Emerg Microbes Infect. 2020;9:221-36.

21. Centers for Disease Control and Prevention. Interim guidance on breastfeeding for a mother confirmed or under investigation for COVID-19. Available from: https://www.cdc.gov/coronaviru s/2019-ncov/specific-groups/pregnancy-guidance-breastfeeding. html. Accessed 19 Feb 2020.

22. Chen H, Guo J, Wang C, et al. Clinical characteristics and intrauterine vertical transmission potential of COVID-19 infection in nine pregnant women: a retrospective review of medical records. Lancet. 2020;395:809-15.

23. Rasmussen SA, Smulian JC, Lednicky JA, et al. Coronavirus disease 2019 (COVID-19) and pregnancy: what obstetricians need to know. Am J Obstet Gynecol. 2020. https://doi.org/10.1016/j. ajog.2020.02.017. 